\title{
The features of distraction behaviour and their relationship with physical condition in Rufous Bush Chats
}

\author{
F. Alvarez ${ }^{1,3}$ and C. SÁnchez ${ }^{2}$ \\ ${ }^{1}$ Estación Biológica de Doñana, CSIC, Apartado postal 1056, E-41080 Sevilla, Spain \\ ${ }^{2}$ Hospital Universitario Virgen Macarena, Departamento de Bioquímica Clínica, Calle \\ Doctor Fedriani s/n, Sevilla, Spain
}

\begin{abstract}
Parent Rufus Bush Chats Cercotrichas galactotes perform of distraction display, approaching and flying away from potential predators near their nests while vocalizing and displaying their conspicuously coloured tail. The response of breeding pairs attending their first brood during the mid and final nestling stages was registered to stimuli of danger near their nests over two seasons. The first stimulus was a human observer standing by the nest and then following the parent in an experiment of distraction (first and last distances and direction of flights were recorded), the second stimuli were a Little Owl and a Corn Bunting mounts (latency and rate of tail-up were measured). For the most part, males and females did not differ in their responses. Breeding pairs were matched in first distance. Chats showed higher latency towards the control and higher tailup rate towards the owl model. The males' rate of tail-up was proportional to the size of the defended brood, and males of smaller body size showed longer last distance. The relationship of the distraction behaviour with condition (body weight / keel length, haematocrit and leukocyte index) was investigated under stepwise multiple linear regression. In males higher haematocrit values were related to higher rates of tail-up display. Higher deposits of fat in the interclavicular depression were related in males to higher tail-up rates, and in females to closer first distance, and to higher number of flights away from the defended nest during the distraction experiment. In conclusion, distraction behaviour appear to depend on short- and long-term condition.
\end{abstract}

KEY WORDS: Cercotrichas galactotes, distraction behaviour, nest defence, physical condition, tail display.

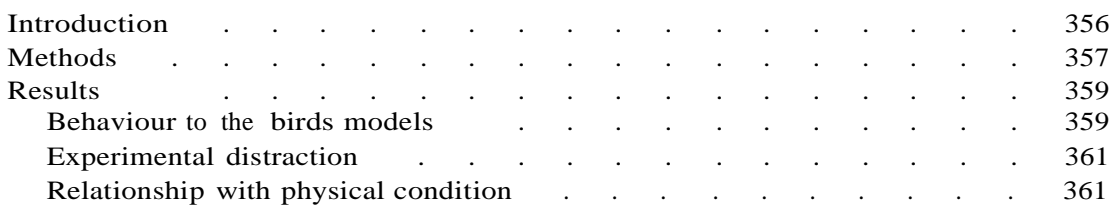

\footnotetext{
${ }^{3}$ Corresponding author: Fernando Alvarez (E-mail: alvarez@ebd.csic.es).
} 


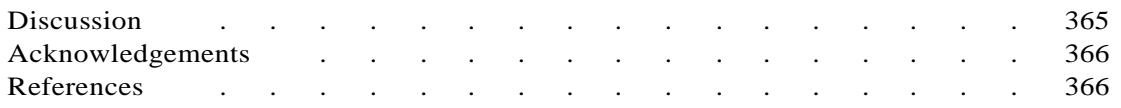

\section{INTRODUCTION}

Parent birds can minimize nest depredation (often a major cause of nesting failure, RICKLEFs 1969) by recognizing their enemies (GOTTFRIED 1979, PATTERSON et al. 1980, НАTCH 1997) and effectively defending their nests (ANDERSSON et al. 1980, Malan \& Jenkins 1996, Cresswell 1997, Olendorf \& Robinson 2000). Differences in levels of avian nest defence have been explained as resulting from allocation of reproductive effort in relation to survival of current and future broods, and more specifically to parental experience, confidence of paternity, number, age, quality and vulnerability of offspring, nest accessibility and conspicuousness, progressive breeding cycle and season, and risk posed by the predator (ANDERSSON et al. 1980, Montgomerie \& WeAtherheAd 1988, REDONDO 1989). The relative contribution of the pair members to nest defence also varies in monogamous passerines from males investing more than females (PAVEL \& BUREŠ 2001), or vice-versa (CAWTHORN et al. 1998), to no sex-difference observed (GREIG-SMITH 1980, NEALEN \& BREITWISCH 1997). On the other hand, breeding pairs of biparental passerines are sometimes matched in their levels of defence (NEALEN \& BREITWISCH 1997), the effects of nest defence being enhanced through the co-operation of both parents (REGELMANN \& CURIO 1986, BYRKJEDAL 1987).

Instead of direct aggression towards the potential nest predator, parental nest defence may take the form in various bird species of a strategy of distraction, the defensive parents trying by various manoeuvres to attract the potential predator towards them, luring it from the nest. The effectiveness of this strategy would be enhanced if the protective parents show conspicuous plumage coloration (deflexion coloration, COTT 1940, BAKER \& PARKER 1979), which would help in drawing the attention of potential predators towards the displaying parent, and away from offspring.

Nest defence may carry substantial costs in terms of energy and risks of injury or death (MYERs 1978, DENSON 1979). If parents must decide how much to invest when faced with a predator, we should expect those in poor physical condition to reduce the amount of energy used for nest defence, and consequently to lower the level of defence (as shown for blood parasite infected Tengmalm's Owl Aegolius funereus, HAKKARAINEn et al. 1998).

Parent Rufous Bush Chats Cercotrichas galactotes carry out a distraction display, approaching the potential predator when near the nest (while vocalizing and performing wing-jerking and tail-up displays) and flying in various directions (around, towards and away from predator and nest), again vocalizing and displaying at each landing. If one loses sight of the distracting bird, its calls and frequent tail-up (up and down tail movements, often cocking it vertically, and sometimes fanning it and showing the distinct black and white patches) signal its position on ground or bushes. A similar display of the black and white tail, also in the predator context, has been described for the Northern Mockingbird (Mimus polyglottos, HAILMAN 1963).

The present study aims at understanding the characteristics of the distraction display of Rufous Bush Chats defending their nests, as well as exploring the relationship between the activities of distraction and the birds' physical condition.

The Rufous Bush Chat is a monogamous and biparental passerine which in the area of study holds exclusive breeding territories, and builds open-cup nests within $1.5 \mathrm{~m}$ from the ground. This species is monomorphic in plumage, and males are slightly larger than females. Both sexes build the nest, and only the female incubates the eggs, being very occasionally fed by males. Egg and nestling stages are about 13 and 12 days, respectively, although disturbed nestlings can leave the nest earlier. Nestlings are fed by both parents. Males and females have 
cryptic light brown plumage with long rufous slightly graduated tail whose central pair of feathers have no marks and the other five pairs are boldly marked with terminal white and subterminal black patches (López 1983; Alvarez 1996, 1997, 2000; Palomino et al. 1999).

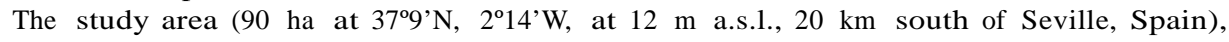
of Mediterranean climate, is mostly used for intensive vineyard agriculture (Rufous Bush Chats build their nests nearly always on vine stocks, which are 1-1.5 m high), with orchards, greenhouses, interspersed fruit trees, and areas of kitchen gardens and vegetable growing. Work was conducted during the reproductive seasons (April to August) of 2000 and 2001. Rufous Bush Chat pairs were caught with mist nets, either near the nest or attracted toward a recorded song as a decoy near the usual singing posts of the males, immediately after the eggs hatched in the first brood of the season (in May and June, also including the first days of July in 2001). Immediately after being captured, they were measured and ringed with a steel numbered ring and a unique combination of 2-3 coloured plastic rings, in order to recognize them individually. The subjects were also weighed (Pesola spring balance with $\pm 0.1 \mathrm{~g}$ precision), and their keel was measured (digital calliper with $\pm 0.01 \mathrm{~mm}$ precision), twice by the same person. Keel length was used as an index of body size (SENAR \& PASCUAL 1997), and body weight / keel length as one of the indices of condition.

Blood samples were also taken from the brachial vein of the subjects by venipuncture, and two capillaries were assayed for haematocrit. Blood was kept on ice for up to 3 hr before processing, and capillaries were centrifuged at $11500 \mathrm{rpm}$ for $8 \mathrm{~min}$ in a portable centrifuge (Bayer M 1101), to obtain the haematocrit value. In addition, a drop of blood was collected in a microcapillary tube, and then transferred to a clean glass slide, smeared, air dried, and fixed in absolute ethanol for $10 \mathrm{~min}$ (to avoid damage from over-bleeding, only one smear was obtained per bird). Slides were stained following the May Grünwald-Giemsa technique. Blood parasites and leukocyte counts were made on 100 fields under oil, using magnification of $\times 100$. While absolute numbers were used for blood parasites counts, a leukocyte index was obtained by multiplying the leukocyte count of each bird by its observed PCV (CAMPBELL 1995, modified). A third of the samples was examined twice in order to obtain a measure of repeatability.

The members of the captured pairs were sexed behaviourally (only females incubate, and only males sing), and according to the presence of incubation patch in females. Although information was collected for all males and females captured in 2000 and 2001, seven males and five females were captured in both years, and were included only once in the analysis (the 2000 data were used). Since we were not able to obtain a complete data set from all of the breeding pairs (nor from all pair members), sample sizes vary in different calculations.

The two values obtained for keel length, body weight / keel length, haematocrit and leukocyte index (from the leukocyte counts and the two capillaries per bird) were used to calculate the repeatability correlation coefficients, as well as to obtain the mean values used in calculations.

All individuals were also scored for the size of the subcutaneous fat reserves in the interclavicular depression and for the condition of the pectoral muscle. The fat score ranged during the period of study from 0 (no visible fat, tracheal pit deeply depressed), to 1 (a thin layer of fat at bottom of pit), 2 (some fat at base of pit, but less than half full), and 3 (tracheal pit at least half full but still below level of clavicles). The pectoral muscle score ranged from 0 (keel prominent, muscle concave, markedly depressed) to 1 (keel detectable but not prominent, muscle slightly concave).

In order to avoid the potential effects on nest defence of the progressive breeding cycle and breeding season (Anderssonet al. 1980, Greig-Smith 1980, Regelmann \& Curio 1983, 
REDONDO 1989), only pairs rearing first broods of nestlings of the same age were used. Within 27 days of capture the response of breeding pairs to several stimuli of danger was tested. We measured their reaction once to the presence beside the nest of one of us (F. Alvarez) when the chicks of their first brood were 6-8 days old, and once again, 3 days later (when chicks were 9-11 days old), to two bird stimuli. These test were always conducted between 9:00 and 11:00 a.m.

When recording the birds' response to the human observer, the latter approached each nest and remained standing $0.5 \mathrm{~m}$ from it. If within $15 \mathrm{~min}$ any of the two members of the breeding pair was visible and performing any of the behaviours of alarm (tail and/or wing movements and alarm calls), the distance to the nest (measured with $\pm 1 \mathrm{~m}$ precision at the end of the trial) and the identity of the bird was recorded. Then, while trying to reproduce a successful sequence of distraction, the observer walked in a straight line and always at approximately the same speed in the direction of the bird, stopping each time that it flew and walking again when it landed, while recording on tape the direction of the flight (either maintaining distance or flying towards or away from nest). After 10 such flights the observer stopped following and measured the final distance of the bird to the nest. After a break of 20 min away from the area, the observer returned to the nest and waited for the other member of the pair in a new trial. From these obervations, first and last distances to the nest and number of flights away from the nest (out of the 10 flights) were obtained.

The response of each breeding pair was also elicited to two bird stimuli: to a taxidermic mount of a Litle Owl (Athene noctua, known to prey on young leaving the nest and still unable to fly, and frequently observed being harassed by breeding Rufous Bush Chat pairs near their nests), and, as a control, to a mounted Corn Bunting (Emberiza calandra, also present in the area). Both models were in upright, perched posture on a dull black iron pole, and were placed facing the nest at a distance of $0.5 \mathrm{~m}$ and $0.5 \mathrm{~m}$ above the level of the nest. The order of presentation of the two stimuli (with a 20 min interval) was alternated from one pair to the next.

The model birds were placed in position by one person when the parent birds were out of view, and while one observer remained stationary at $70-100 \mathrm{~m}$ from the nest. The person who placed the models then withdrew from the immediate area. Now one observer, aided by a second one, and both equipped with $10 \times$ binoculars and 40-60 $\times$ telescope, registered the time that elapsed between model placement and the appearance of an individual parent bird that responded for the first time with any of the behaviours of alarm the observer counted the number of tail-up displays performed by each of the parents during a 5 min period. Latency time $( \pm 1 \mathrm{~min})$ to respond (parent birds that failed to show were assigned the maximum value plus 1 , i.e. $16 \mathrm{~min}$ ) and rates of tail-up were obtained from these records.

Instead of combining several aspects of nest defence, we chose to deal with the different activities (latency, first and last distances, number of flights, and tail-up) separately.

\section{Statistical analysis}

The variables of nest defence considered were first and last distance, number of flights away from nest, latency and rate of tail-up, and those of body condition were body weight / keel length, hematocrit, leukocyte index, blood parasites count, and fat and pectoral muscle scores.

The features of distraction behaviour were studied under nonparametric paired analyses (mates within pairs, or a bird acting as its own control). Means were compared by the Wilcoxon matched-pairs signed-ranks, and the Spearman rank correlation tests (SIEGEL \& Castellan 1988). The sequential Bonferroni test (Sokal \& RohlF 1995) was used to limit the overall error.

The relationship of the variables of defence with the indicators of body condition (except the scores for fat and pectoral muscle condition) was estimated with stepwise multiple linear regression (ZAR 1996). Separate analyses were done for males and females. The distributions of hematocrit were transformed by arcsin, and the remainder variables by $\log _{10}$ $(\mathrm{X}+1)$. The transformed variables did not deviate significantly from the normal distribution (Kolmogorov-Smirnov test).

Nonparametric tests (Kruskal-Wallis ANOVA and Mann-Whitney U test, SIEgEL \& CAstellan 1988) were used in the analysis of the distraction behaviour in relation to fat and pectoral muscle scores.

The repeatibility of the twice recorded variables were all high (intraclass reliability coefficients $\left.r_{1}>0.810, P<0.001\right)$ except for blood parasites counts $\left(r_{1}=0.226, P=0.158\right)$, probably due to the frequent null values.

Since information for 2000 and 2001 relative to the variables analyzed was found to be not significantly different, data for these 2 years were pooled. All tests were two-tailed. 


\section{Behaviour to the bird models}

Male and female bush chats responded differently to the owl and bunting models, but male responses were similar to female responses. Comparisons of the chats' response towards the two stimuli showed a shorter latency of both sexes when arriving near the mounted owl than when arriving near the control (males: $\mathrm{T}=196.5, \mathrm{n}=$ 46, $P=0.052$; females: $\mathrm{T}=171, \mathrm{n}=46, P=0.050$; Wilcoxon signed-ranks test), and although both sexes showed higher rates of tail-up towards the owl mount than towards the control, the comparison was significant only for males (males: $T=19, n$ $=26, P<0.001$; females: $\mathrm{T}=53, \mathrm{n}=19, P=0.091$ ) (Fig. 1). Male and female responses with respect to the bird models did not differ except for the females' higher rates of tail-up when displaying towards the control (Table 1 and Fig. 1).

The two variables of nest defence against the owl model were positively related to each other, but significantly so only for females (latency vs tail-up rate; males: $\mathrm{n}=38, \mathrm{r}_{\mathrm{s}}=0.133, P=0.498$; females: $\left.\mathrm{n}=36, \mathrm{r}_{\mathrm{s}}=0.371, P=0.031\right)$.

Table 1.

Male-female differences in the measure recorded during presentation of the models and the distraction experiment (Wilcoxon signed-ranks test, $\mathrm{T}$ being the smaller of the sums of the like-signed ranks) and within-pairs correlations (Spearman rank correlation test).

\begin{tabular}{lccccc}
\hline & \multicolumn{2}{c}{ Male-female difference } & & \multicolumn{2}{l}{ Within-pairs correlation } \\
\cline { 2 - 3 } \cline { 5 - 6 } & $\mathrm{T}$ & $\mathrm{n}$ & & $\mathrm{r}_{\mathrm{s}}$ & $\mathrm{n}$ \\
\hline Model presentation & & & & \\
$\quad$ Latency to owl model (min) & 273.0 & 46 & & 0.298 & 46 \\
Latency to control model (min) & 57.5 & 46 & & 0.295 & 46 \\
Tail-up to owl model (per min) & 146.0 & 29 & & -0.286 & 29 \\
Tail-up to control model (per min) & $33.0 *$ & 18 & & 0.163 & 18 \\
Distraction experiment & & & & 33 \\
First distance (m) & 171.0 & 33 & & $0.572^{* *}$ & 32 \\
Last distance (m) & 208.0 & 32 & & 0.290 & 32 \\
Number of flights & 129.0 & 32 & & 0.322 & 31 \\
\hline
\end{tabular}

${ }^{*} P<0.05,{ }^{* *} P<0.01$. Results of correlations corrected using the sequential Bonferroni test $(\mathrm{k}=4$ and $\mathrm{k}=3$ for model presentation and distraction experiment, respectively). 
LATENCY (MIN) TO BIRD MOUNTS

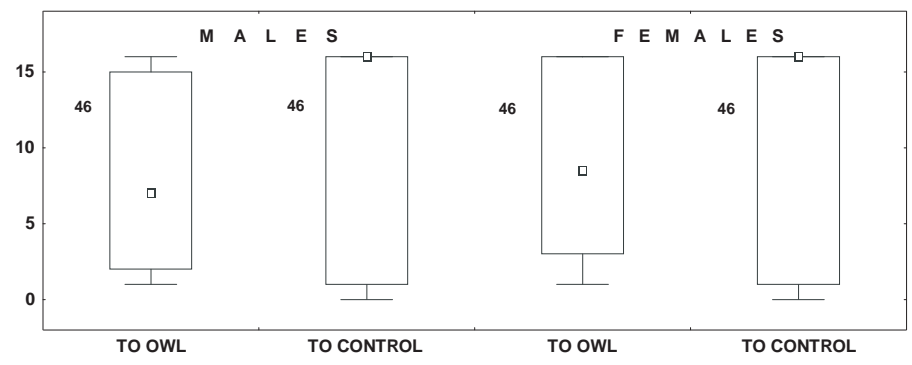

TAIL-UP (PER MIN) TO BIRD MOUNTS

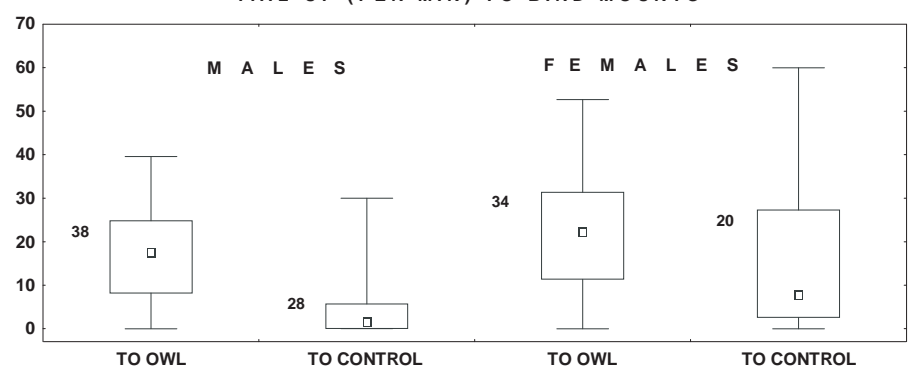

DISTANCE (M) IN DISTRACTION EXPERIMENT

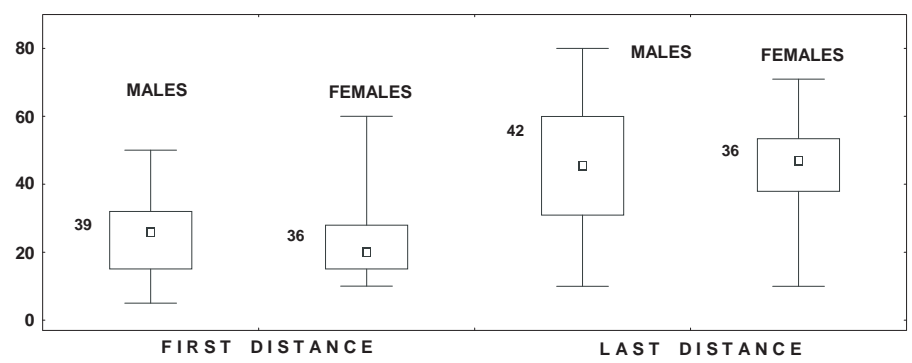

NUMBER OF FLIGHTS IN DISTRACTION EXPERIMENT

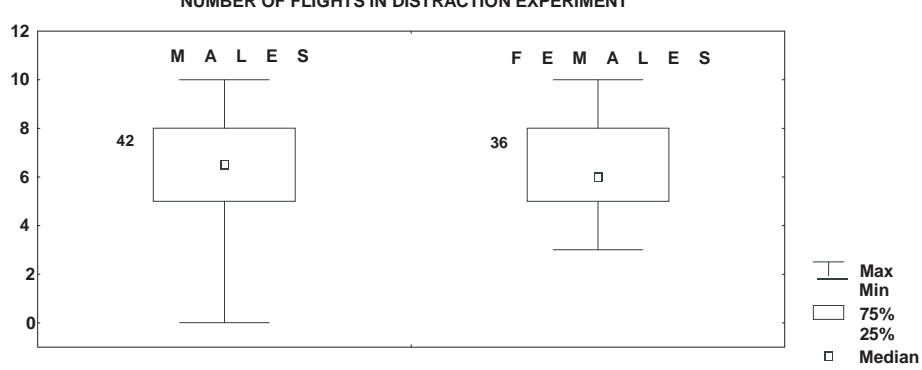

Fig. 1. $\square$ The responses of male and female Rufous Bush Chats to model presentation (latency and tail-up rate) and experimental distraction (first and last distances and number of flights away from nest). The number of cases is indicated near the box \& whiskers. 
Of the two activities recorded during the owl model presentation, only the males' tail-up rate was significantly (and positively) related to the size of the defended brood (Table 2).

\section{Experimental distraction}

In 46 out of 49 pairs tested, at least one parent was present. Of the 46, in 42 the males were present and in 37 the females were present. No difference between the sexes was observed (McNemar test: $X^{2}=1.79$, df $=1, P=0.182$ ). When both pair members came to display, no male-female differences were found in any of the three recorded activities (Table 1 and Fig. 1). On the other hand, male and female responses to the experimental distraction was positively correlated within pairs for the three recorded activities, although at a significant level only for first distance (Table 1, Fig. 2A).

With respect to the relationship among the three variables of nest defence in the context of experimental distraction, only the males' last distance was significantly (and positively) correlated with the number of flights away from the nest $\left(\mathrm{r}_{\mathrm{s}}\right.$ $=0.448, \mathrm{n}=42, P=0.003$ ).

Body size (as expressed by keel length) was negatively related with the males' last distance (i.e. the smaller their body size, the farther the males flew away from their nests during the manoeuvres of distraction, Table 2 and Fig. 2B).

\section{Relationship with physical condition}

The indicators of body condition were significantly related to each other in two cases: between body weight / keel and haematocrit in males $\left(r_{s}=0.364, n=45\right.$, $P=0.014)$, and between haematocrit and leukocyte index in females $\left(\mathrm{r}_{\mathrm{s}}=0.513, \mathrm{n}=\right.$ $35, P=0.002)$.

Table 2 .

Spearman rank correlation between the nest defence variables of the distraction experiment (first and last distances and number of flights away from nest) and of the Little Owl presentation (latency and tail-up rate) and body size (keel length) and size of defended brood.

\begin{tabular}{|c|c|c|c|c|c|c|c|c|}
\hline & \multicolumn{4}{|c|}{ Males } & \multicolumn{4}{|c|}{ Females } \\
\hline & \multicolumn{2}{|c|}{ Body size } & \multirow{2}{*}{$\begin{array}{l}\text { Brood } \\
\mathrm{r}_{\mathrm{s}}\end{array}$} & \multirow{2}{*}{$\begin{array}{c}\text { size } \\
\mathrm{n}\end{array}$} & \multicolumn{2}{|c|}{ Body size } & \multirow{2}{*}{$\begin{array}{c}\text { Brood } \\
r_{s}\end{array}$} & \multirow{2}{*}{$\begin{array}{c}\text { size } \\
\mathbf{n}\end{array}$} \\
\hline & $r_{s}$ & $\mathrm{n}$ & & & $r_{\mathrm{s}}$ & $\mathrm{n}$ & & \\
\hline \multicolumn{9}{|l|}{ Owl presentation } \\
\hline Latency & 0.129 & 43 & -0.212 & 43 & 0.299 & 39 & 0.153 & 43 \\
\hline Tail-up & -0.009 & 36 & $0.494 * *$ & 38 & 0.243 & 31 & -0.342 & 32 \\
\hline \multicolumn{9}{|c|}{ Distraction experiment } \\
\hline First distance & 0.078 & 38 & -0.106 & 39 & -0.109 & 32 & -0.168 & 34 \\
\hline Last distance & $-0.411^{*}$ & 40 & 0.088 & 40 & -0.145 & 31 & 0.318 & 33 \\
\hline Number of flights & -0.074 & 40 & 0.226 & 40 & -0.008 & 31 & 0.249 & 33 \\
\hline
\end{tabular}

$* P<0.05$, ** $P<0.01$. Results corrected using the sequential Bonferroni test $(\mathrm{k}=2$ and $\mathrm{k}=3$ for model owl presentation and distraction experiment, respectively). 

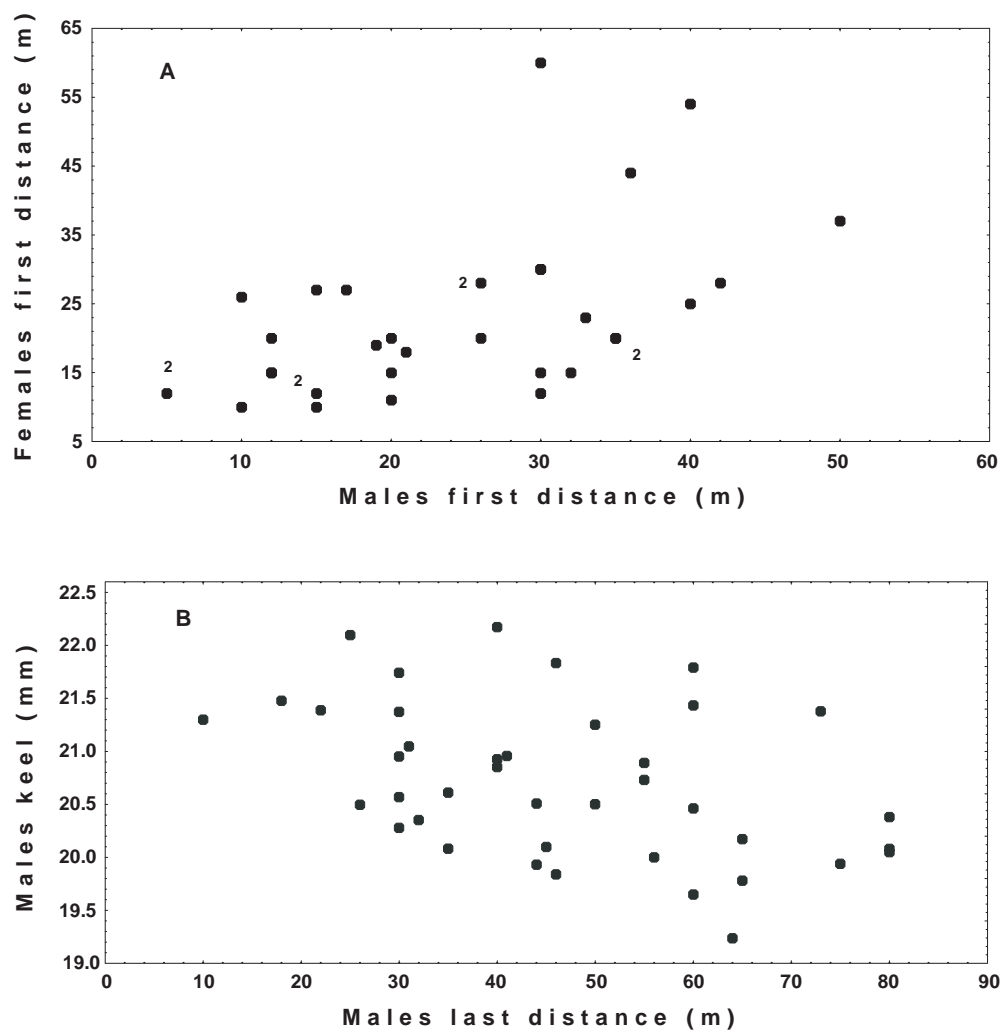

Fig. 2. $\square$ (A) The relationship between mates with respect to their distance to the nest and the human beside it when first arriving to alarm (first distance). (B) The relationship between the distance of males to the nest at the end of the experiment of distraction (last distance) and their body size (keel length). The number of cases with the same value are indicated near the datapoints.

Multiple regression of the three indicators of body condition on each of the five behaviours of distraction produced significant results only in males, and only for the tail-up display rate, which was positively affected by their haematocrit $\left(\log _{10}\right.$ [tail-up rate] $=-2.13+0.39 \arcsin$ [haematocrit] $)\left(\mathrm{F}_{2,25}=4.754, \mathrm{n}=28, P=0.018\right)$ (Fig. 3).

With respect to the effect of the size of the subcutaneous fat reserves on the behaviour of defence, the males (whose scores ranged from 0-2) showed no effect on their level of latency, first and last distances, and number of flights away from nest $(\mathrm{H}=0.291, \mathrm{n}=36 ; \mathrm{H}=5.583, \mathrm{n}=38 ; \mathrm{H}=3.723, \mathrm{n}=40 ; \mathrm{H}=2.826, \mathrm{n}=40$; respectively, $P>0.05$; Kruskal-Wallis ANOVA), but there was a significant effect on tail-up rate $(\mathrm{H}=13.994, \mathrm{n}=36, P<0.001)$. In the case of females (whose fat score ranged from 0-3), their fat deposits showed no effect on their level of latency, last distance, and tail-up rate $(\mathrm{H}=7.151, \mathrm{n}=34 ; \mathrm{H}=6.304, \mathrm{n}=35 ; \mathrm{H}=3.013, \mathrm{n}=34$; 


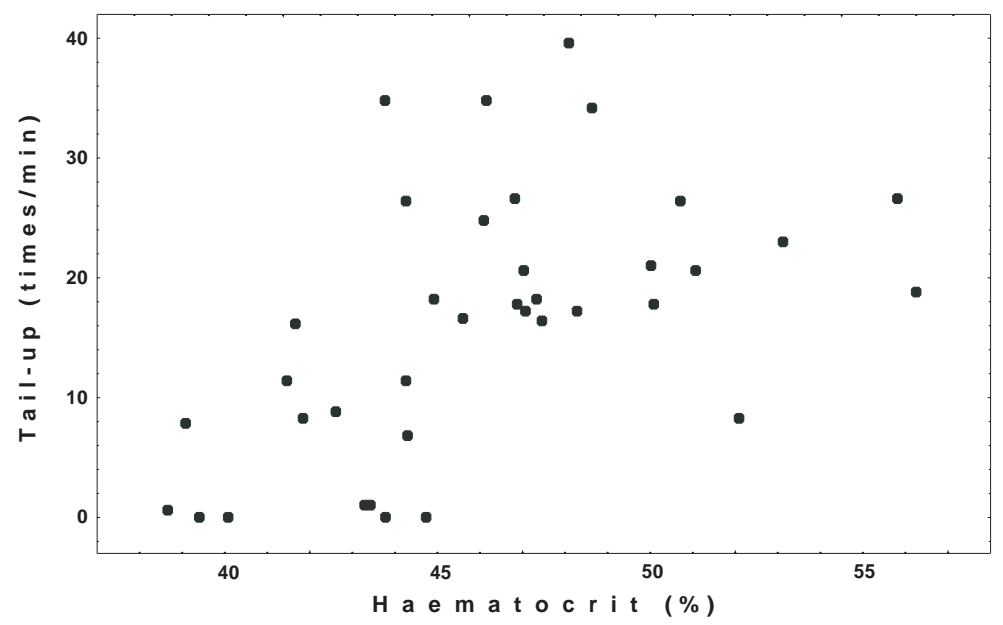

Fig. 3. $\square$ Relationship between haematocrit value and rate of tail-up display of Rufous Bush Chat males during the behaviour of distraction towards an owl model $\left(\mathrm{r}_{\mathrm{s}}=0.608, \mathrm{n}=37, P<0.001\right.$, Spearman rank correlation).

respectively, $P>0.05$ ), but significant effects were shown on first distance and number of flights away from nest $(\mathrm{H}=10.358, \mathrm{n}=36, P=0.016 ; \mathrm{H}=12.188, \mathrm{n}=$ 35, $P=0.007$; respectively).

Males with the two lower fat scores ( 0 and 1$)$ were significantly similar in their tail-up rates $(U=97, P=0.985$; Mann-Whitney $U$ test $)$, and both showed lower tail-up rates than males with a score of $2(\mathrm{U}=0.5, P<0.001 ; \mathrm{U}=1.5, P=$ 0.002 , respectively) (i.e., the higher the males' fat deposits the higher their level of the tail-up display, Fig. 4).

Of the females with the four fat scores, those with the two lower ones ( 0 and 1 ) and those with the two higher ones (2 and 3) were similar to each other with respect to their first distance to the nest and the human beside it $(\mathrm{U}=38.5, P=$ $0.181 ; \mathrm{U}=17.5, P=0.716$, respectively), while those with the two lower ones ( 0 and 1) showed significantly (or quasi-significantly) higher first distance than those with the two higher scores ( 2 and 3$)(0$ vs 2 and 3 : $U=15, P=0.014$; $U=5, P=0.044 ; 1$ vs 2 and 3: $U=30, P=0.029 ; U=10.5, P=0.074$; respectively). In other words, the bigger the females' fat stores the closer they approached the nest and the human beside it when first arriving to alarm (Fig. 4).

Females with scores 0 and 1 were significantly similar in their number of flights away from the nest during the distraction experiment $(U=41.5, P=0.362)$, as well as those with scores 1 and $2(\mathrm{U}=32, P=0.059)$, and 2 and $3(\mathrm{U}=10, P=$ $0.144)$. Nevertheless females with the lowest score $(0)$ showed significantly lower number of flights than those with each of the two higher scores $(0$ vs 2 : $U=14, P=$ 0.010 ; 0 vs $3: \mathrm{U}=2, P=0.012$ ), and females with score 1 also showed lower number of flights than those with the highest fat score (3) ( $U=5, P=0.019$ ). In other words, as can be seen in Fig. 3, the bigger the females' subcutaneous fat deposits the higher the number of flights away from the nest during the distraction experiment (Fig. 4). 

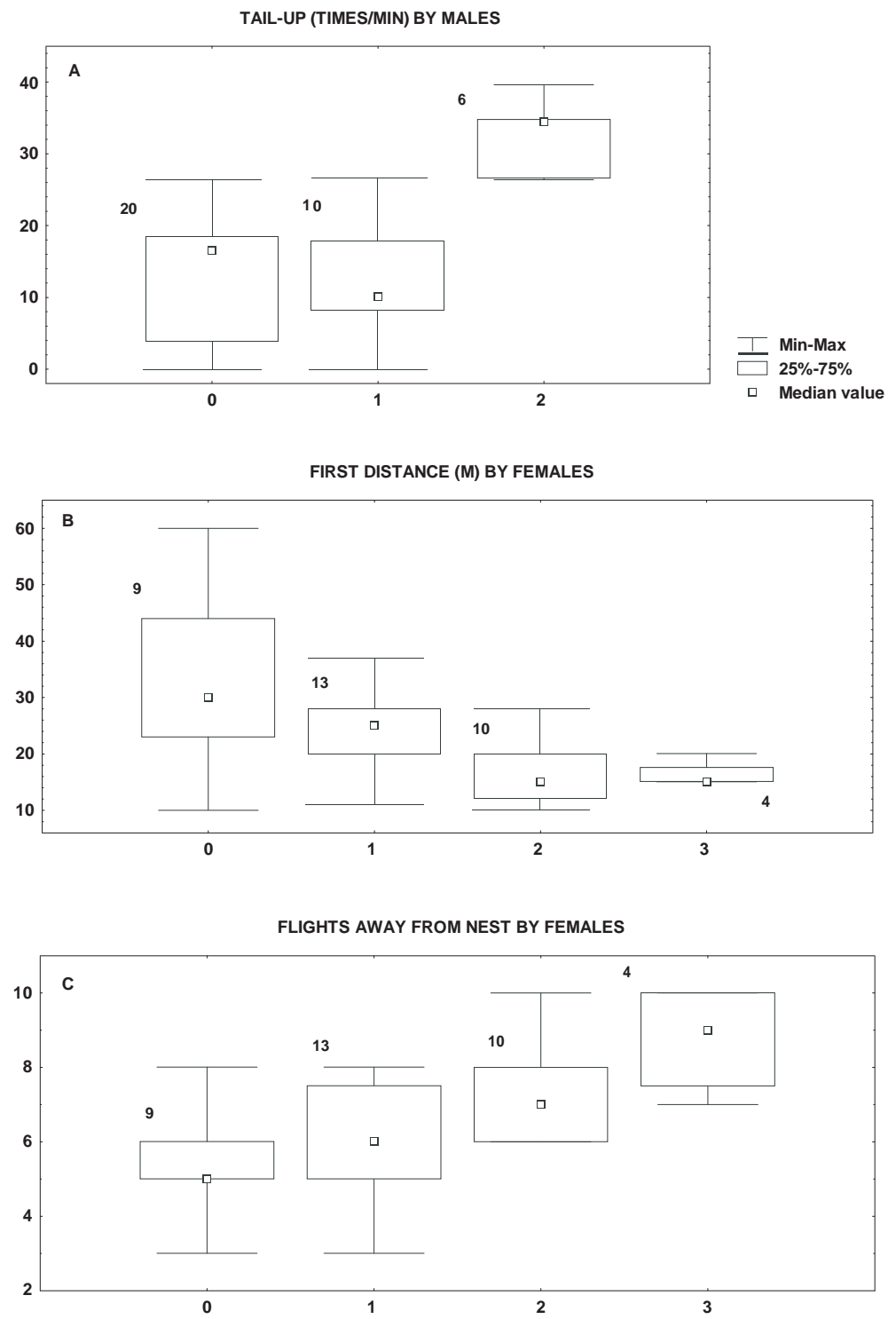

Fig. 4. $\square$ The relationship of fat classes with tail-up rate in male Rufous Bush Chats (A), and with distance of females to nest and human beside it when first arriving to defend (first distance) and their number of flights away from nest during the distraction experiment (B and $\mathrm{C}$, respectively). The number of cases is indicated near the box \& whiskers.

No significant relationship was found between the condition of the pectoral muscle and the behaviour of distraction. All females showed score 0 , and out of 47 males, 42 showed score 0 and 5 showed score 1 (males; first distance: $U=45.5$; last 
distance: $U=67.5$; number of flights away from nest: $U=65.5$; latency: $U=57.5$; tail-up: $\mathrm{U}=57.5 ; P>0.05$ ).

\section{DISCUSSION}

Rufous Bush Chats apparently quickly recognize the arrival of their enemy, coming earlier and displaying more intensely towards it. We would expect this behaviour to contribute in some way to the protection of the progeny (Cresswell 1997, Olendorf \& Robinson 2000). Both sexes appear to contribute similarly to nest defence (as reported by Greig-Smith 1980 and NEAlen \& BReitwisch 1997 for two other passerine species), at least during the mid and final nestling stages of their first brood. The higher tail-up rate of females towards the control model is probably of no great consequence, as they do not seem to differentiate the experimental from the control models in that respect.

The fact that in most observations pair mates were present confronting the danger jointly, as well as the positive correlation found between mates in their first distance to nest and human during the experiment of distraction, point to some degree of co-ordination of the pair members in nest attendance. It is not clear, however, if they co-operate in nest defence.

Males of smaller body size fly farther from the nest during nest defence and larger males remaining closer to nest and predator. This could reflect an enhanced distracting ability in smaller males while larger males perhaps put more emphasis on direct anti-predator aggression.

The positive correlation between nest defence and brood size, amply observed in other passerines (Greig-Smith 1980, Møller 1984, Knight \& Temple 1986, Curio \& Onnebrink 1995) (but see Robertson \& Biermann 1979, Redondo \& Carranza 1989, HALUPKA 1999) was expressed in male Rufous Bush Chats by the rate of their tail-up display, and support the prediction that birds invest more in larger broods than in smaller ones (CURIO 1987).

With respect to the relationship found between distraction behaviour and physical condition, since haematocrit reflects erythrocyte volume and is a good short-term indicator of anabolism and condition in wild birds (CARPENTER 1975, Merilä \& Svensson 1995, Brown 1996, Svensson \& Merilä 1996, Wanless et al. 1997), its positive effect on tail-up rate in male chats suggests an adaptation to the demands of the tail muscles involved in the display (which can reach up to 19 tailups per min during prolonged periods in some birds) for an increased uptake and efficient transfer of oxygen to them. The likely advantage for males capable of rapid and sustained movements of the conspicuous tail would be to attract predators from longer distances. Nevertheless, since the tail-up rate in males has been shown to be positively related to the size of the defended brood, it could be that the relationship of haematocrit with tail-up rate is of an indirect nature, high haematocrits being associated with exercise-induced polycythaemia, as a response to the requirements of an elevated oxygen-carrying capacity of the blood during increased work load when parents are raising large broods (as found by HõRAK et al. 1998 for parent Great Tits Parus major). On the other hand, Fig. 3 suggests a dependence of the males tail-up display rate on "optimal haematocrit" (BIRCHARD 1997): while a high haematocrit value in wild birds is usually a good indicator of condition, low levels are sometimes related to bacterial infection and gastrointesti- 
nal disorders, and very high values may indicate disease or dehydration (CAMPBELL 1995, Schlosberg et al. 1996, Оts et al. 1998).

Although the ability of visible fat scores to predict total body reserves varies among bird species, there are examples of high levels of determination in several passerines (BROwN 1996), and the size of subcutaneous fat deposits has been shown to reflect body condition (Merilä \& SVEnsson 1995). The relationship found between the fat score and the rate of the tail-up display in males points to a dependence of the latter on an adequate reserve of fat to provide the energy required for muscular effort. The same would apply to the relationship of the females' fat score to their first distance to nest and predator and to their number of flights away from nest during distraction, the assumption being that these two elements of the strategy imply greater levels of activity. The risk involved in close approaches to predator must be accompanied with enough stamina for rapid escape, and flying away from the nest probably involves greater effort than flying around or towards it.

The fact that fatter birds practise more elaborate distractions, taking greater risks, contradicts previous information of heavier birds being slower and less manoeuvrable while flying and less skilfull taking off (WitTER et al. 1994, Metcalfe \& Ure 1995, Norberg 1995, Kullberg et al. 1996). It may be that birds are able to adjust the characteristics of flight (angle of ascent, velocity, aceleration, manoeuvrability) to the current conditions (such as increased predation risk), so that small increases of fat load would have no effect on flight skilfulness (KuLLberG 1998, VEASEY et al. 1998).

\section{ACKNOWLEDGEMENTS}

We thank M. Vázquez, N. Varo, R. Ruiz and P. Jurado for help during field observations, and E. Aguilera and J.A. Amat for comments. Funding was provided by the Ministry of Science and Technology of Spain (PB98-0494-CO2-01, BOS2001-0541).

\section{REFERENCES}

Alvarez F. 1996. Variation in the song rate during the breeding cycle of the Rufous Bush Chat, Cercotrichas galactotes. Ardeola 43: 49-56.

Alvarez F. 1997. The functions of songs and the spatial pattern of song production in the rufous bush chat (Cercotrichas galactotes). Doñana, Acta Vertebrata 24: 67-78.

Alvarez F. 2000. Relationship between tail color pattern and reproductive success, mate acquisition and nest predation in Rufous Bush Chats. Condor 102: 708-712.

Andersson M., Wiklund C.G. \& Rundgen H. 1980. Parental defence of offspring: a model and an example. Animal Behaviour 28: 536-542.

Baker R.R. \& PARker G.A. 1979. The evolution of bird coloration. Philosophical Transactions of the Royal Society of London (B) 287: 63-130.

BIRCHARD G.F. 1997. Optimal hematocrit: theory, regulation and implications. American Zoologist 37: 65-72.

Brown M.E. 1996. Assessing body condition in birds, pp. 67-135. In: Nolan V. \& Ketter E.D., Edits. Current ornithology, Vol. 13. New York: Plenum Press.

ByrkJEDAl I. 1987. Antipredator behavior and breeding success in Greater Golden-Plover and Eurasian Dotterel. Condor 89: 40-47.

Campbell T.W. 1995. Avian hematology and cytology. Ames, Iowa: Iowa State University Press.

CARPENTER F.L. 1975. Bird hematocrits: effect of high altitude and strength of flight. Comparative Biochemical Physiology 50: 415-417.

Cawthorn J.M., Morris D.L., Ketterson E.D. \& Nolan V. 1998. Influence of experimentally elevated testosterone on nest defence in Dark-eyed Juncos. Animal Behaviour 56: 617-621. 
Cotт H.B. 1940. Adaptive coloration in animals. London: Methuen. Cresswell W. 1997. Nest predation: the relative effects of nest characterisitcs, clutch size and parental behaviour. Animal Behaviour 53: 93-103.

Curio E. 1987. Brood defence in the Great Tit: the influence of age, number and quality of young. Ardea 75: 35-42.

Curio E. \& Onnebrink H. 1995. Brood defense and brood size in the Great Tit (Parus major): a test of the model of unshared parental investment. Behavioral Ecology 6: 235-241.

Denson R.D. 1979. Owl predation on a mobbing crow. Wilson Bulletin 91: 133.

GotTfried B.M. 1979. Anti-predator aggression in birds nesting in old field habitats: an experimental analysis. Condor 81: 251-257.

Greig-Smith P.W. 1980. Parental investment in nest defence by Stonechats (Saxicola torquata). Animal Behaviour 28: 604-619

Hakkarainen H., Ilmonen P., Koivunen V. \& KorpimäKi E. 1998. Blood parasites and nest defense behaviour of Tengmalm's owls. Oecologia 114: 574-577.

Hailman J.P. 1963. The Mockingbird's “tail-up” display to mammals near the nest. Wilson Bulletin 75: 414-417.

HALUPKA L. 1999. Nest defence in an altricial bird with uniparental care: the influence of offspring age, brood size, stage of the breeding season and predator type. Ornis Fennica 76: 97-105.

НАтсн M. 1997. Variation in song sparrow nest defense: individual consistency and relationship to nest success. Condor 99: 282-289.

Hõrak P., Ots I. \& Murumägi A. 1998. Haematological health state indices of reproducing Great Tits: a response to brood manipulation. Functional Ecology 12: 750-756.

Knight R.L. \& Temple S.A. 1986. Nest defence in the American Goldfinch. Animal Behaviour 34: $887-897$

Kullberg C. 1998. Does diurnal variation in body mass affect take-off ability in wintering willow tits? Animal Behaviour 56: 227-233.

Kullberg C., Fransson T. \& Jakobsson S. 1996. Impaired predator evasion in fat blackcaps (Sylvia atricapilla). Proceedings of the Royal Society of London (B) 263: 1671-1675.

López G. 1983. Datos sobre la nidificación del Alzacola (Cercortrichas galactotes). Alytes 1: 373-392.

Malan G. \& Jenkins A.R. 1996. Territory and nest defence in polyandrous Pale Chanting Goshawks: do co-breeders help? South African Journal of Zoology 31: 170-176

Merilä J. \& Svensson E. 1995. Fat reserves and health state in migrant Goldcrest Regulus regulus. Functional Ecology 9: 842-848.

Metcalfe N.B. \& Ure S.E. 1995. Diurnal variation in flight performance and hence potential predation risk in small birds. Proceedings of the Royal Society of London (B) 261: 395400 .

Montgomerie R.D. \& Weatherhead P.J. 1988. Risks and rewards of nest defence by parent birds. Quaterly Review of Biology 63: 167-187.

Møller A. 1984. Parental defence of offspring in the Barn Swallow. Bird Behaviour 5: 110117.

Myers J.P. 1978. One deleterious effect of mobbing in the Southern Lapwing (Vanellus chilensis). Auk 95: 419-420.

Nealen P.M. \& Breitwisch R. 1997. Northern Cardinal sexes defend nests equally. Wilson Bulletin 109: 269-278.

Norberg U.M. 1995. How a long tail and changes in mass and wing shape affect the cost for flight in animals. Functional Ecology 9: 48-54.

Olendorf R. \& Robinson S.K. 2000. Effectiveness of nest defence in the Acadian Flycatcher. Ibis 142: 365-371. 
Ots I., Murugämi A. \& Hõrak P. 1998. Haematological health state indices of reproducing Great Tits: methodology and sources of natural variation. Functional Ecology 12: 700707.

Palomino J.J., Martín-Vivaldi M. \& Soler M. 1999. Determinants of reproductive success in the Rufous Bush Robin (Cercotrichas galactotes). Journal für Ornithologie 140: 467-480.

Patterson T.L., Petrinovich L. \& James D.K. 1980. Reproductive value and appropiatedness of response to predators by White-crowned Sparrows. Behavioral Ecology and Sociobiology 7: 227-231.

Pavel V. \& Bureš S. 2001. Offspring age and nest defence: test ot the feedback hypothesis in the Meadow Pipit. Animal Behaviour 61: 297-303.

REDondo T. 1989. Avian nest defence: theoretical models and evidence. Behaviour 111: 161195.

Redondo T. \& CARranza J. 1989. Offspring reproductive value and nest defense in the Magpie (Pica pica). Behavioral Ecology and Sociobiology 25: 369-378.

Regelmann K. \& Curio E. 1983. Determinants of brood defence in the great tit Parus major L. Behavioral Ecology and Sociobiology 13: 131-345.

Regelmann K. \& Curio E. 1986. How do Great Tit (Parus major) pair mates cooperate in brood defence? Behaviour 97: 10-36.

Ricklefs R.E. 1969. An analysis of nesting mortality in birds. Smithsonian Contributions to Zoology 9: 1-48.

Robertson R.J. \& Biermann G.C. 1979. Parental investment strategies determined by expected benefits. Zeitschrift für Tierpsychologie 50: 124-128.

Senar J.C. \& Pascual J. 1997. Keel and tarsus legth may provide a good predictor of avian body size. Ardea 85: 269-274.

Schlosberg A., Bellaiche M., Zeitlin G., Ya'Acobi M. \& Cahaner A. 1996. Hematocrit values and mortality from ascites in cold-stressed broilers from parents selected by hematocrit. Poultry Science 75: 1-5.

Siegel S. \& Castellan N.J. 1988. Nonparametric statistics for the behavioral sciences. New York: McGraw-Hill.

Sokal R.R. \& RohlF F.J. 1995. Biometry. New York: Freeman.

SVEnsson E. \& MERILÄ J. 1996. Molt and migratory condition in Blue Tits: a serological study. Condor 98: 825-831.

Veasey J.S., Metcalfe N.B. \& Houston D.C. 1998. A reassessment of the effect of body mass upon flight speed and predation risk in birds. Animal Behaviour 56: 883-889.

WANLESS S., BARTON T.R. \& HARRIS M. 1997. Blood hematocrit measurements of four species of North Atlantic seabirds in relation to levels of infestation by the tick Ixodes uriae. Colonial Waterbirds 20: 540-544.

Witter M.S., Cuthill I.C. \& Bonser R.H.C. 1994. Experimental investigations of massdependent predation risk in the European starling, Sturnus vulgaris. Animal Behaviour 48: 201-222.

ZAR J.H. 1996. Biostatistical analysis. Upper Saddle River, New Jersey: Prentice Hall. 